\title{
Simplified finite model based evaluation of tissue stress distribution on anesthetic feet of Leprosy patients for 3 dimensional orthosis fabrication
}

\author{
Sathish K Paul ${ }^{1 *}$, Sudesh Sivarasu ${ }^{2}$ \\ From 4th Congress of the International Foot and Ankle Biomechanics (i-FAB) Community \\ Busan, Korea. 8-11 April 2014
}

\section{Background}

The Subtalar joint position during static stance is a crucial determinant of the peak plantar pressures and forms a base for any intervention in foot related problems for leprosy affected patients[1]. Studies have stated that the subtalar joint when in neutral position is more ideal for orthotic fabrication. In this study a hypothesis was formulated and pursued $[2,3]$. Central to the hypothesis is that the stress will be minimal in the distal joints of the foot when the subtalar joint is neutral at static stance position.

\section{Results}

The Computed Tomography (CT) images of the feet for 5 patients suffering from Hansen's disease having no muscle weakness and joint restriction were acquired. The gray intensities corresponding to the bones of the foot from the CT images were 3 dimensionally reconstructed. The three dimensional model of the human foot, incorporating the realistic geometry and the material properties of the hard tissues were then analyzed using a finite element solver. Stress distribution on bones of the foot while on static stance with the subtalar joint in neutral position were acquired. The results demonstrate that the weight of the patient and the position of the calcaneum in the static stance position contribute to the high stresses in the foot. The stresses in the bones of the foot are minimal when the subtalar is in neutral position, suggesting that this position is an optimal aim for foot orthotic fabrication.

\section{Conclusion}

The automating process of designing a customized orthosis with the impression got from the 3 dimensionally modeled feet reduced the modeling time considerably. The simple technique used will help in giving comfort and stability to the patient's feet while walking.

\section{Authors' details}

'VIT University, Vellore - 632014, Tamil Nadu, India. ${ }^{2}$ Lecturer \& Project leader, Biomechanics, University of Cape Town, Cape Town 7925, South Africa.

Published: 8 April 2014

\section{References}

1. Abbud GA, Li KZ, DeMont RG: Attentional requirements of walking according to the gait phase and onset of auditory stimuli. Gait \& posture 2009, 30(2):227-32

2. Al-Yahya E, Dawes H, Smith L, Dennis A, Howells K, Cockburn J: Cognitive motor interference while walking: a systematic review and metaanalysis. Neuroscience and biobehavioral reviews 2011, 35(3):715-28.

3. Brown CN, Padua DA, Marshall SW, Guskiewicz KM: Variability of motion in individuals with mechanical or functional ankle instability during a stop jump maneuver. In Clinical biomechanics. Volume 24. Bristol, Avon; 2009:(9):762-8.

doi:10.1186/1757-1146-7-S1-A91

Cite this article as: Paul and Sivarasu: Simplified finite model based evaluation of tissue stress distribution on anesthetic feet of Leprosy patients for 3 dimensional orthosis fabrication. Journal of Foot and Ankle Research 2014 7(Suppl 1):A91.

\footnotetext{
* Correspondence: sathishpaul77@gmail.com

'VIT University, Vellore - 632014, Tamil Nadu, India

Full list of author information is available at the end of the article
} 